\title{
Clearance of Natural Surfactant Phosphatidylcholine from 3-Day-Old Rabbit Lungs: Effects of Dose and Species
}

\author{
ANDREA PETTENAZZO, KOUKI OGUCHI, STEVEN SEIDNER, MACHIKO IKEGAMI, \\ DAVID BERRY, AND ALAN JOBE
}

Department of Pediatrics, Harbor-UCLA Medical Center, UCLA School of Medicine, Torrance, California 90509

\begin{abstract}
Surfactants were labeled in vivo with [ $\left.{ }^{3} \mathrm{H}\right]$ choline and the large aggregates of the surfactant were recovered by alveolar wash and centrifugation. The labeled natural surfactants from rabbit, sheep, cat, and pig were injected into the airways of 3-day-old rabbits, and the percent recoveries of the labeled surfactant-associated phosphatidylcholine were measured in alveolar washes, lung tissue after alveolar wash, and in the lungs (alveolar wash plus lung tissue). The rabbit surfactant-associated phosphatidylcholine was cleared from the lungs at a constant $15.6 \pm 1.8 \%$ per $24 \mathrm{~h}$ (mean $\pm \mathrm{SE}$ ) of the injected doses of surfactant that contained from 0.41 to $10.2 \mu \mathrm{mol}$ phosphatidylcholine. At all times following injection, approximately $50 \%$ of the labeled phosphatidylcholine remaining within the lungs was recovered in the alveolar wash and $50 \%$ with the lung tissue. The percent clearances for sheep, cat, and pig surfactant phosphatidylcholine in rabbits were $12.5,16.6$, and $16.3 \%$ per $24 \mathrm{~h}$, respectively, values not different from that measured for rabbit surfactant. The results documented a slow clearance of exogenously administered surfactant phosphatidylcholine as a fixed percent of the injected dose that was unchanged by species source of the surfactant. (Pediatr Res 20: 11391142, 1986)
\end{abstract}

\section{Abbreviation}

RDS, respiratory distress syndrome

Clinical trials using surfactants from animal sources for the treatment of RDS demonstrated acute improvements in pulmonary function, decreased pulmonary associated complications of RDS, and improved long-term outcomes (1-5). Clinical trials using synthetic surfactants documented less convincing responses $(6,7)$. The surfactants from animal sources were used in humans without apparent problems relating to cross-species sensitization (8). Several clinical trials documented prolonged responses of infants to single doses of surfactant, suggesting that the material remained within the lungs for a long period of time $(2,8)$. The rate of loss of small amounts of labeled species specific natural surfactant from the lungs of newborn rabbits and lambs was very slow relative to the rate of loss from adult rabbit lungs (9-11). Large doses of natural surfactant also were cleared slowly from developing rabbit lungs (12). However, the dependence of sur-

Received April 1, 1986; accepted June 12, 1986.

Reprint requests to Alan Jobe, M.D., Ph.D., Harbor-UCLA Medical Center, Bldg. A-17, 1000 W. Carson Street, Torrance, CA 90509

Supported by Grant HD-11932 from Child Health and Development, Department of Health and Human Services. A.P. was supported in part by Consiglio Nazionale delle Ricerche, Grant 85.00746.56. factant clearance rate on dose or species source of the surfactant has not been carefully evaluated. Therefore, we report the relationship between dose and clearance rate of rabbit natural surfactant phosphatidylcholine in rabbits and the clearance from rabbit lungs of natural surfactant phosphatidylcholine from sheep, cats, and pigs.

\section{MATERIALS AND METHODS}

Natural surfactants. Natural surfactants were radiolabeled by injecting $5 \mathrm{mCi}\left[{ }^{3} \mathrm{H}\right.$ ]choline into the airways of a 3-day-old lamb, a 1-wk-old pig, and an adult cat. Rabbit surfactant was radiolabeled by injecting $1 \mathrm{mCi}\left[{ }^{3} \mathrm{H}\right]$ choline into the airways of each of ten 3-day-old rabbits (10). The labeled choline was synthesized from redistilled dimethylethanolamine and $\left[{ }^{3} \mathrm{H}\right]$ methyl iodide (ICN) using $\mathrm{NaOH}$ as a catalyst according to Smith et al. (13). Approximately $24 \mathrm{~h}$ after isotope injection, the airways and alveoli of the animals were washed with $0.9 \% \mathrm{NaCl}$. The large surfactant aggregates were recovered as a pellet following centrifugation at $7000 \times g$ for $30 \mathrm{~min}$. The resuspended pellet was layered over $0.7 \mathrm{M}$ sucrose in saline and centrifuged at $8500 \times$ $g$ for $30 \mathrm{~min}$. The white layer at the interface was recovered, pelleted, and resuspended in saline for storage at $-20^{\circ} \mathrm{C}$ (14). Unlabeled surfactant also was recovered from alveolar washes of other animals not injected with radioisotope. The surfactant isolation procedure recovers only the large aggregate forms of the natural surfactant that contain about $40 \%$ of the phosphatidylcholine in the alveolar washes and are the most surface active fraction of surfactant from alveolar washes (15). Such surfactant is effective for the treatment of preterm lambs with surfactant deficiency (14). Each species-specific labeled surfactant was mixed with the appropriate unlabeled natural surfactant to adjust the specific activity before tracheal injection.

Administration of surfactants. Each 3-day-old rabbit was given an intratracheal injection of a surfactant using a 27 - or 30-gauge needle following exposure of the trachea through an approximately $1 \mathrm{~cm}$ longitudinal skin incision in the neck (10). Each surfactant was suspended in $0.45 \mathrm{M} \mathrm{NaCl}$ and injected in a volume of 0.2 or $0.3 \mathrm{ml}$. One hundred thirty-two 3-day-old rabbits were divided into five groups and were injected with natural rabbit surfactant suspensions containing $0.6,1.6,2.9$, 5.1 , or $10.2 \mu \mathrm{mol}$ surfactant-associated phosphatidylcholine labeled with about $0.06 \mu \mathrm{Ci}\left[{ }^{3} \mathrm{H}\right]$ choline. Thirty-four rabbits each received sheep surfactant containig $3.5 \mu \mathrm{mol}$ phosphatidylcholine, 36 rabbits each received cat surfactant containing $0.8 \mu \mathrm{mol}$ phosphatidylcholine, and 31 rabbits each received pig surfactant containing $2.8 \mu \mathrm{mol}$ phosphatidylcholine. The pool size of surfactant recoverable by alveolar wash from the lungs of 3-day-old rabbits is about $6 \mu \mathrm{mol}$ phosphatidylcholine so that the injected test surfactants were between 10 and $170 \%$ of the endogenous pool (10). The rabbits were hand fed with Esbelac and subse- 
quently were sacrificed with pentobarbital in groups of four to six animals at times from 3 to $74 \mathrm{~h}$ after surfactant injection.

Processing of samples. The airway and alveolar surfactant was recovered by a thorough alveolar wash using 4 to $5 \mathrm{ml}$ of $0.9 \%$ $\mathrm{NaCl}$ infused to fully distend the lungs and withdrawn repetitively three times. This procedure was repeated with four more saline volumes and the five washes were pooled (10). The washed lungs then were homogenized, and lipids were extracted from aliquots of the alveolar washes and lung homogenates with chloroform:methanol (16). Phosphatidylcholine was isolated from the lipid extracts by thin-layer chromatography in one dimension (10). The phosphatidylcholine spots were scraped into vials and radioactivity was measured in a liquid scintillation counter using Aquasol II (New England Nuclear) as a counting fluid. The amount of radioactivity in each surfactant was estimated from triplicate aliquots of each injection solution following lipid extraction and thin-layer chromatography. The amount of phosphatidylcholine was measured using the phosphate assay of Bartlett (17).

Data analysis. All results are shown as percent recoveries of the injected doses of the natural surfactants, corrected for the loss of labeled phosphatidylcholine that was noted previously soon after surfactant injection (10). This loss probably represented surfactant coughed out of the airways immediately following injection. In these experiments, the amount present at 0 time was defined as the $Y$ axis intercept of the linear regression of the recovery of radiolabeled phosphatidylcholine in the lung (alveolar wash plus lung tissue). Across the eight groups of rabbits the 0 time intercepts were $80 \pm 7 \%$ of the quantities actually injected. For each experiment the rate of clearance was calculated using the 0 time intercept value. About $10 \%$ of the animals were excluded from the analysis because the recoveries were $>2 \mathrm{SD}$ lower than the values for the mean of the timed sacrifice group in which the animal belonged. These low recoveries were attributed to inadequate tracheal injections. All data are expressed as means \pm SE. Linear regression analysis by the method of least squares was used to calculate clearance rates.

\section{RESULTS}

The clearance curves for the lowest dose of rabbit surfactant are shown in Figure 1. The rate of clearance of the injected dose was calculated from the slope of the linear regression curve as $12 \%$ per $24 \mathrm{~h}$. Since the injected dose corrected for initial losses was $0.41 / \mathrm{mol}$ phosphatidylcholine, $0.049 \mu \mathrm{mol}$ labeled phosphatidylcholine $/ 24 \mathrm{~h}$ was lost from the lungs. The curves for clearance of labeled phosphatidylcholine from the alveolar washes and lung tissues indicated that approximately $50 \%$ of the labeled phosphatidylcholine was associated with the alveolar washes and $50 \%$ with the lung tissue at all times after surfactant injection.

The rate of clearance of the rabbit surfactant-associated phosphatidylcholine was calculated for the data sets for the five doses of rabbit surfactant (Fig. 2). The amount of labeled phosphatidylcholine that was cleared from the lungs was $15.6 \pm 1.8 \%$ of the injected dose $/ 24 \mathrm{~h}$. The values across the data sets were quite reproducible, independent of surfactant dose (Table 1). The distribution of the labeled phosphatidylcholine was about $47 \%$ in the alveolar wash and $53 \%$ in the lung tissue. The contributions of the alveolar and lung tissue-associated phosphatidylcholines to the lung clearance rate were similar.

The rates of clearance of the sheep, cat, and pig surfactants were measured at doses that were at the lower end of the doseclearance curve measured for rabbit surfactant. The percent clearances $/ 24 \mathrm{~h}$ were $12.5 \%$ for sheep surfactant, $16.6 \%$ for cat surfactant, and $16.3 \%$ for pig surfactant (Fig. 3). These clearance rates were not different from that measured for rabbit surfactant in rabbits. Also, the percent associations of the labeled phosphatidylcholine with the alveolar washes and lung tissue were not different between species.

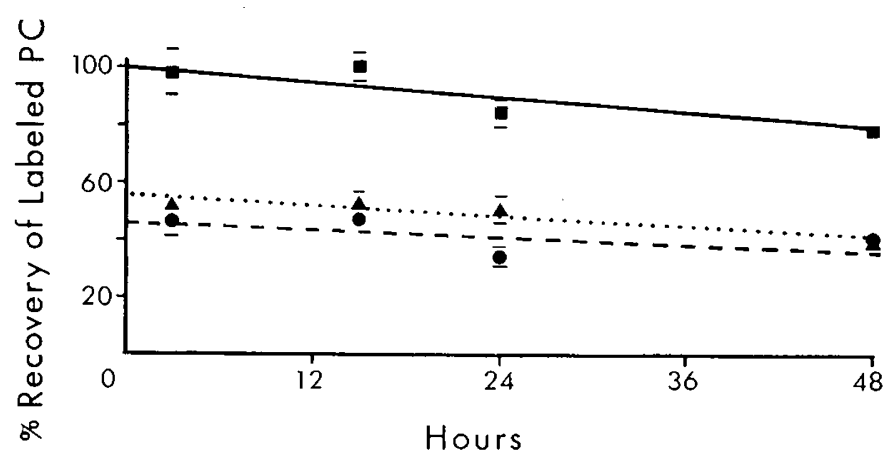

Fig. 1. Clearance of labeled natural surfactant phosphatidylcholine $(P C)$ from rabbit lungs following tracheal injection. Rabbits were injected with $0.6 \mu \mathrm{mol}$ surfactant associated phosphatidylcholine. The 0 time intercept of the regression line for lung yielded a corrected injected dose of $0.41 \mu \mathrm{mol}$ phosphatidylcholine. The recoveries are expressed as percent of the 0 time intercept value for alveolar washes $(\bullet)$, lung tissue (A), and lung ( $(\boldsymbol{\omega})$.

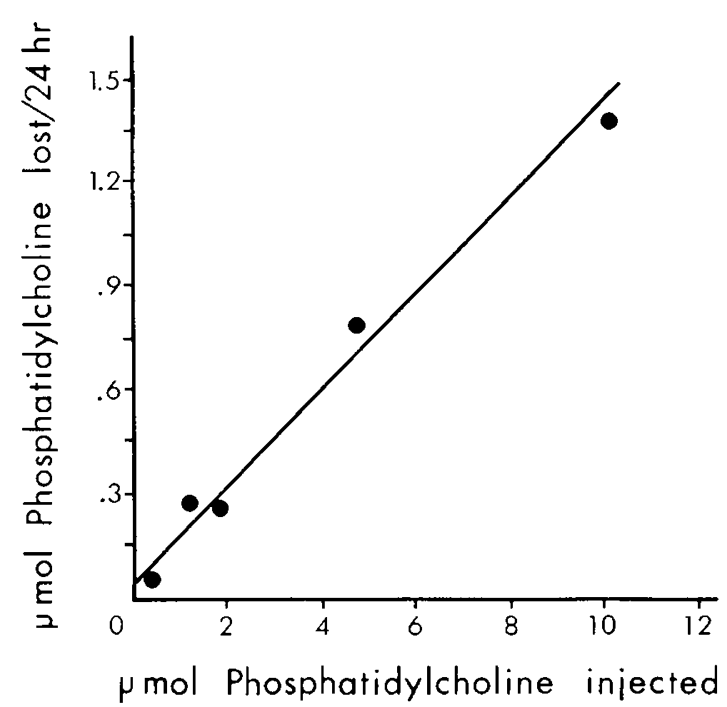

Fig. 2. Relationship between amount of rabbit surfactant phosphatidylcholine $(P C)$ injected and the rate of clearance $/ 24 \mathrm{~h}$ calculated from the slopes of the regression curves for clearance from lungs. Clearance was linearly correlated with the dose injected $(r=0.99)$.

Table 1. Mean values of regression lines for loss of labeled rabbit surfactant phosphatidylcholine at five different doses

\begin{tabular}{|c|c|c|c|}
\hline & Slope $(\% / \mathrm{h})$ & Intercept (\%) & $r$ \\
\hline Alveolar wash & $-0.30 \pm 0.07$ & $47 \pm 3$ & $0.644 \pm 0.118$ \\
\hline Lung tissue & $-0.37 \pm 0.05$ & $53 \pm 3$ & $0.883 \pm 0.020$ \\
\hline Alveolar wash + lung tissue & $-0.67 \pm 0.09$ & 100 & $0.852 \pm 0.063$ \\
\hline
\end{tabular}

\section{DISCUSSION}

The interpretation of clearance of the labeled surfactant-associated phosphatidylcholine has been simplified by assuming linear relationships. If large numbers of animals and groups of animals are studied, the data can be resolved into nonlinear curves, especially in the first several hours after tracheal injection of the surfactant $(10,11)$. These experiments characterize overall clearance and ignore nonlinear relationships by using relatively few groups of animals at widely spaced time intervals. For 


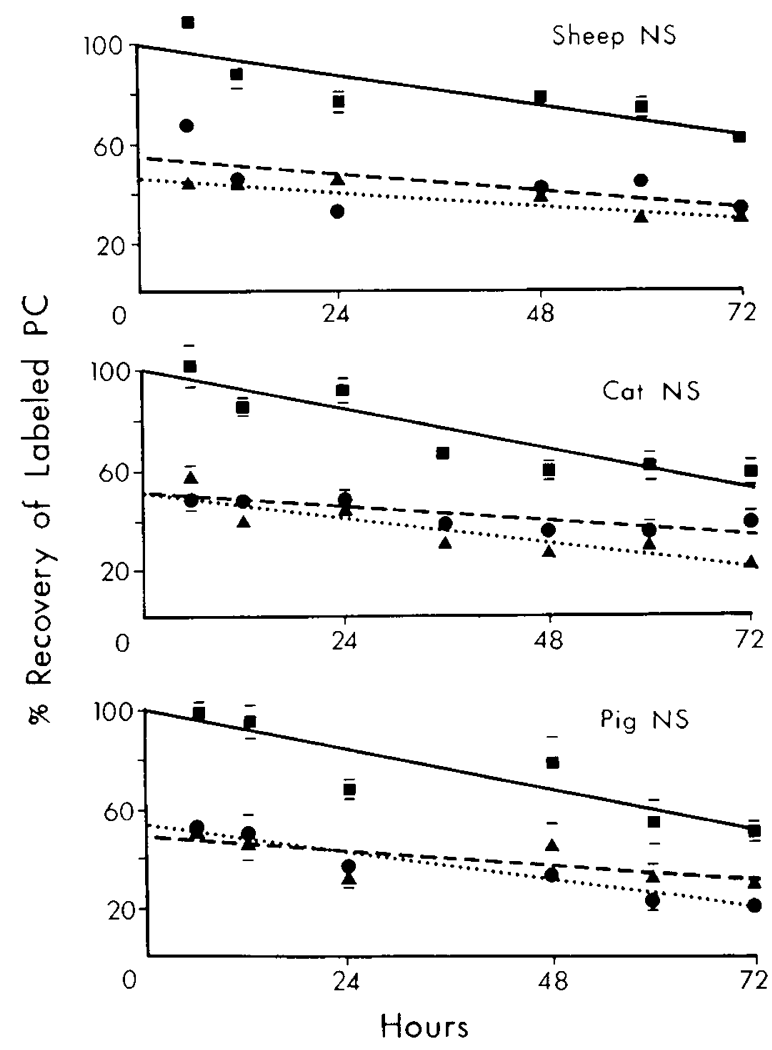

Fig. 3. Clearance in rabbit lungs of labeled phosphatidylcholine $(P C)$ from species heterologous natural surfactants. Species source of the surfactant $(N S)$ is indicated on each figure. The clearance curves are shown for alveolar washes $(\boldsymbol{\bullet})$, lung tissue $(\boldsymbol{\Lambda})$, and lung (⿻). The data are shown as means $\pm \mathrm{SE}$, with the SE bars shown only if they fell outside the data points.

comparative purposes such an analysis seems reasonable, although statements concerning surfactant reprocessing cannot be made based on these data sets $(10,11)$.

The rate of clearance of different surfactants or phospholipid suspensions have been estimated previously. Geiger et al. (18) noted the exponential clearance of a dipalmitoyl-phosphatidylcholine aerosol from rat lungs with a biological half-life of about $4.3 \mathrm{~h}$. Oyarzun et al. (19) found that unilamellar liposomes were cleared from adult rabbit lungs at a rate of $7.8 \% / \mathrm{h}$, and the clearance rate was almost doubled by increased ventilation. Hallman et al. (20) reported that radiolabeled natural surfactant was cleared from the airways and alveoli of adult rabbits to lung tissue, and the labeled phospholipids became in part associated with lamellar bodies. These observations suggested that alveolar surfactant might be recycled back into type II cells for reprocessing and resecretion. While others speculated that recycling might be quite efficient $(20,21)$, we found that only about $23 \%$ of the alveolar phosphatidylcholine was recycled in adult animals (11). These clearance studies were performed with doses of surfactant that were small relative to the endogenous pool sizes present in the animals.

Based on the above relatively rapid clearance rates estimated for adult animals, the potential usefulness of surfactant replacement therapy for RDS could be severely compromised. Fortunately the developing lung metabolizes surfactant differently from the mature lung. The turnover times for alveolar surfactant phosphatidylcholine are longer and the recycling pathways seem to be much more efficient, resulting in a much slower overall rate of clearance of exogenously administered surfactants (10). The biological half-life for radiolabeled phosphatidylcholine as- sociated with natural surfactant in term lamb lungs was about 7 days (9), and more than $50 \%$ of labeled phosphatidylcholine could be recovered from 3-day-old rabbit lungs 3 days after tracheal injection $(10,12)$. However, the clearance rates and pathways of clearance probably depend critically on the type of surfactant tested. Large doses of liposomes of dipalmitoylphosphatidylcholine were cleared more rapidly than were comparable doses of the liposomes that had been preassociated with natural surfactant in vitro (22). The liposomes do not become tissue associated to nearly the same extent as does the natural surfactant $(12,22)$. A synthetic surfactant (a 7:3 mixture of dipalmitoylphosphatidylcholine:phosphatidylglycerol) was cleared about 6fold more rapidly from the airways of preterm lambs than was a cow lung-derived surfactant (23). The phophatidyglycerol component of a synthetic surfactant given to preterm infants with RDS was not detected in airway samples from these infants 24 $\mathrm{h}$ after treatment, suggesting rapid clearance (7). Clearance rates may be related to the aggregate forms and sizes of different surfactant suspensions (15). In these studies we used only the large, surface active surfactant particles recovered from alveolar washes. Also, clearance rates may be related to the severity of RDS, as less radiolabeled surfactant was recovered from preterm lambs with more severe disease than from lambs with less disease (24). Very little it known about surfactant clearance in the immature lung.

The 3-day-old rabbit is a convenient model for the study of surfactant metabolism. We measured clearance rates of radiolabeled natural surfactants to better define dose-clearance relationships. The high dose of surfactant that we injected into these approximately $65 \mathrm{~g}$ animals represents a surfactant dose of about $160 \mathrm{mg}$ surfactant lipid $/ \mathrm{kg}$. The dose of surfactant used in most clinical trials has been 60 to $100 \mathrm{mg}$ surfactant lipid/kg (1-5). We previously demonstrated that high doses of natural surfactant did not feedback inhibit endogenous surfactant synthetic and secretion pathways (12). This study demonstrates that over a 17fold dose range, the rates of clearance are a fixed percent of the injected dose. The clearance and catabolic pathways of natural surfactant have not been well characterized, but large doses of surfactant do not seem to saturate these pathways. Such a pattern of clearance would be consistent with the nonspecific uptake of a fixed percent of the existing alveolar pool, independent of alveolar pool size. Such a mechanism of bulk uptake also is consistent with the nonspecificity of the reutilization pathways of phosphatidylcholine (25), and the uptake of proteins by type II cells (26).

While the phospholipid composition of natural surfactant is reasonably constant across species, the surfactant specific proteins are immunologically distinct between species, and these proteins may be important for the poorly defined metabolic pathways that regulate surfactant pool sizes (27). Since surfactant from beef lung is being used in clinical trials for infants with RDS, we believed a study of the clearance of natural surfactants from different species would be timely. In a previous study using very high doses of natural surfactants, rabbit surfactant was cleared from rabbit lungs somewhat more rapidly than was sheep surfactant (12). The measured clearance rates were $10.4 \%$ and $20.7 \% / 24 \mathrm{~h}$ for sheep and rabbit surfactants, respectively. These clearance rates bracket the rates measured in this report based on eight separate measurements. The rates of clearance for cat and pig surfactant were numerically identical to the clearance rate for rabbit surfactant in rabbits. When taken together, there is either no or a very small difference in clearance rates across species. Therefore, species specific recognition of the surfactant specific proteins must not be critical to surfactant catabolic pathways. These studies indicating that surfactant is cleared slowly at a fixed percent of dose $/ 24 \mathrm{~h}$ and that species differences do not affect clearance rates are consistent with the prolonged responses to species heterologous surfactants reported in several clinical trials of surfactant for RDS (1-5). 


\section{REFERENCES}

1. Fujiwara T, Chida S, Watabe Y, Maeta H, Morita T, Abe T 1980 Artificial surfactant therapy in hyaline-membrane disease. Lancet 1:55-59

2. Enhorning G, Shennan A, Possmayer F, Dunn M, Chen CP, Milligan J 1985 Prevention of neonatal respiratory distress syndrome by tracheal instillation of surfactant: a randomized clinical trial. Pediatrics 76:145-153

3. Hallman M, Merritt TA, Jarvenpaa A-L, Boynton B, Mannino F, Gluck L, Moore T and Edwards D 1985 Exogenous human surfactant for treatment of severe respiratory distress syndrome: A randomized prospective clinical trial. J Pediatr 106:963-969

4. Kwong MS, Egan EA, Notter RH, Shapiro DL 1985 Double-blind clinical trial of calf lung surfactant extract for the prevention of hyaline membrane disease in extremely premature infants. Pediatrics 76:585-592

5. Shapiro DL. Notter RH, Morin FC. Deluga KS, Golub LM, Sinkin RA, Weiss KL, Cox C 1985 Double-blind, randomized trial of a calf lung surfactant extract administered at birth to very premature infants for prevention of respiratory distress syndrome. Pediatrics 76:593-599

6. Morley CJ, Miller N, Bangham AD 1981 Dry artificial lung surfactant and its effect on very premature babies. Lancet 1:64-68

7. Wilkinson A, Jenkins PA, Jeffrey JA 1985 Two controlled trials of dry artificial surfactant: carly effects and later outcome in babies with surfactant deficiency. Lancet 2:287-291

8. Fujiwara T 1984 Surfactant replacement in neonatal RDS. In: Robertson B, Van Golde LMG, Batenburg JJ (eds) Pulmonary Surfactant. Elsevier Science Publishers, Amsterdam, pp 479-503

9. Glatz T, Ikegami M, Jobe A 1982 Metabolism of exogenously administered natural surfactant in the newborn lamb. Pediatr Res 16:711-715

10. Jacobs H, Jobe A, Ikegami M, Conaway D 1983 The significance of reutilization of surfactant phosphatidylcholine. J Biol Chem 258:4159-4165

11. Jacobs HC, Ikegami M, Jobe AH, Berry DD, Jones S 1985 Reutilization of surfactant phosphatidylcholine in adult rabbits. Biochim Biophys Acta 837:77-84

12. Oguchi K, Ikegami M, Jacobs H, Jobe A 1985 Clearance of large amounts of natural surfactant and DPPC from lungs of 3-day-old rabbits following tracheal injection. Exp Lung Res 9:221-235

13. Smith GA. Montecucco C. Bennett JP 1978 Isotopic labeling of phosphatidylcholine in the choline moiety. Lipids 13:92-94
14. Jobe A, Ikegami M 1984 The prematurely delivered lambs as a model for studies of neonatal adaptation. In: Nathanielsz PW (ed) Animal Models in Fetal Medicine. Perinatology Press, Ithaca, NY, pp l-30

15. Magoon MW, Wright JR, Baritussio A, Williams MC, Goerke J, Benson BJ, Hamilton RL, Clements JA 1983 Subfractionation of lung surfactant. Implications for metabolism and surface activity. Biochim Biophys Acta 750:18-31

16. Bligh EG, Dyer WJ 1959 A rapid method of total lipid extraction and purification. Can J Biochem Physiol 37:911-917

17. Bartlett GR 1959 Phosphorus assay in column chromatography. J Biol Chem 234:466-468

18. Geiger K, Gallagher ML, Hedley-Whyte J 1975 Cellular distribution and clearance of aerosolized dipalmitoyl lecithin. J Appl Physiol 39:759-766

19. Oyarzun MJ, Clements JA, Baritussio A. Ventilation enhances pulmonary alveolar clearance of radioactive dipalmitoylphosphatidylcholine in liposomes. Am Rev Respir Dis 121:709-721

20. Hallman M, Epstein BL, Gluck L 1981 Analysis of labelling and clearance of lung surfactant phospholipids in rabbits. J Clin Invest 68:742-751

21. Baritussio A, Carraro R, Bellina L, Rossi A, Bruni R, Pettenazzo A, Enzi G 1985 Turnover of phospholipids isolated from fractions of lung lavage fluid. J Appl Physiol 59:1055-1060

22. Ikegami M, Jobe A, Duane G 1985 Liposomes of dipalmitoylphosphatidylcholine associate with natural surfactant. Biochim Biophys Acta 835:352-359

23. Egan EA, Notter RH, Kowng MS, Shapiro DL 1983 Natural and artificial lung surfactant replacement therapy in premature lambs. J Appl Physiol 55:875883

24. Solimano A, Bryan C, Jobe A, Ikegami M, Jacobs H 1985 Effects of highfrequency and conventional ventilation on the premature lamb lung. $J$ Appl Physiol 59:1571-1577

25. Jacobs H, Jobe A, Ikegami M, Miller D, Jones S 1984 Reutilization of phosphatidylcholine analogues by the pulmonary surfactant system. The lack of specificity. Biochim Biophsy Acta 793:300-309

26. Williams MC 1984 Endocytosis in alveolar type II cells: effect of charge and size of tracers. Proc Natl Acad Sci USA 81:6054-6058

27. Whitsett JA, Ohning BL, Ross G, Meuth J, Weaver T, Holm BA, Shapiro DL, Notter R 1986 Hydrophobic surfactant-associated protein (SAP 6-14) in whole lung surfactant and its importance for biophysical activity in lung surfactant extracts used for replacement therapy. Pediatr Res 20:460-467 